\title{
DO PROCEDIMENTO DA EXECUÇÃO FISCAL: DA INAPLICABILIDADE DO INSTITUTO DA DESCONSIDERAÇÃO DA PERSONALIDADE JURÍDICA
}

\section{THE TAX EXECUTION PROCEDURE: THE INAPPLICABILITY OF THE INSTITUTE OF THE LEGAL ENTITY DISREGARD}

\section{Gabriela Zucatti Büttner ${ }^{1}$}

Resumo: O presente artigo possui de celeridade de tramitação. Tracomo objetivo a análise da não ta-se de um rito diferenciado em aplicação do incidente da descon- que é necessária a observância sideração da personalidade jurí- dos regramentos específicos da dica no âmbito das ações de exe- matéria. A agilidade na tramitação cução fiscal. Ainda, estudar-se-á a do procedimento fiscal é um dos origem do incidente nos processos principais motivos da não aplijudiciais e a sua normatização pelo cação do incidente. Observa que Código de Processo Civil de 2015. se trata de cobranças de créditos Demonstrar-se-á que as ações de públicos que visam a toda uma execução fiscal possuem procedi- coletividade. No caso de exismento próprio ante a necessidade tir a necessidade de quitação dos

1 Pós-Graduada em especialização em Direito Público e Privado pela Escola Superior da Magistratura do Estado de Santa Catarina (ESMESC), orientada pelo Professor Doutor Cristhian Magnus De Marco, PhD. Graduada em Direito pela Universidade do Oeste de Santa Catarina (UNOESC), campus Joaçaba. Técnica Administrativa Estadual do Tribunal de Justiça de Santa Catarina. E-mail: gzbuttner@gmail.com 
créditos de maneira satisfatória, haverá sim a desconsideração da personalidade jurídica. No presente artigo, demonstrar-se-á que a desconsideração ocorre dentro do próprio procedimento, tendo em vista a necessidade de celeridade e economia processual. Salienta-se que o procedimento resguarda os direitos e as garantias individuais e coletivas previstas na Constituição e no ordenamento brasileiro. Também, neste artigo, se demonstrará que a desconsideração da personalidade jurídica observa o contraditório e a ampla defesa dos sócios-administradores da pessoa jurídica executada.

Palavras-chave: Execução fiscal. Doutrina da desconsideração. Desconsideração da Personalidade Jurídica. Princípio da Dignidade Humana.

Abstract: The purpose of this article is to analyze the non-application of the incident of disregard of legal personality in the context of tax enforcement procedure. It will also study the origin of the incident in legal proceedings and its standardization by the Civil Procedure Code of 2015. The study will demonstrate that tax enforcement actions have their own procedure because of their need to be processed quickly. This is a differentiated rite in which compliance with the specific rules of processing is necessary. The agility in the handling of the tax procedure is one of the main reasons for the non-application of the incident. It is emphasized that the procedure safeguards individual and collective rights and guarantees prescribed in the Constitution and in Brazilian law. If there is a need to quote credits satisfactorily, there is no disregard for the legal personality. It is show that disregard occurs within the procedure itself, in view of the need for speed and procedural savings. It is emphasized that the procedure safeguards individual and collective rights and guarantees prescribed for in the Constitution and in our Brazilian law. The article demonstrated that disregard of legal personality observes the contradictory and a full defense principles of the administrators involved in the executed legal entity.

Keywords: Tax execution. Disregard Doctrine. Disregard Legal Entity. Constitutional Human Dignity Principle.

\section{INTRODUÇÃO}

No presente trabalho, demonstrar-se-á que o procedimento especial previsto para as ações de execução fiscal impede 
a aplicação do incidente da desconsideração da personalidade jurídica, o qual foi introduzido no ordenamento brasileiro pelo Novo Código de Processo Civil. Dessa forma, tal instituto, será analisado pela ótica das ações de execução fiscal, a qual possui um desenvolvimento processual mais célere, porquanto almeja a quitação de créditos com destinação pública para a satisfação de toda a sociedade.

Discorrer-se-á sobre a prevalência da celeridade no trâmite processual das ações de execução fiscal, o que culmina no afastamento de práticas morosas à execução, como é o caso de abertura de um incidente processual.

Ainda, no presente trabalho, se tratará sobre a importância de ser realizado de forma regular o deferimento ao redirecionamento do feito em face dos sócios que detêm a administração da sociedade empresária. Demonstrar-se-á que é necessário que seja oportunizado o contraditório e a ampla defesa, a fim de evitar nulidades procedimentais.

Neste trabalho, também serão verificadas as oportunidades em que a Fazenda Pública poderá requerer a indisponibilidade de bens dos sócios-administradores, como é o exemplo dos casos de confusão patrimonial, desvio de finalidade e dissolução irregular da sociedade.

Tal estudo é importante tendo em vista que, muitas vezes, durante o curso do processo, não foi possível realizar a citação pessoal da empresa executada, tendo sido seguida pela publicação em Edital. Dessa forma, há a possibilidade de que, após ter havido a baixa na empresa, o administrador acredite que não há débitos para serem quitados. Contudo, talvez por falta de instrução, a pessoa física acaba sendo surpreendida, após alguns anos de encerramento da atividade, com o fato de existirem valores a serem quitados com o fisco.

Dito isso, mostrar-se-á que é necessário garantir que se tenha um efetivo contraditório a fim de evitar uma lide moro- 
sa e prejudicial às partes. Salienta-se que a pressa para quitar os créditos públicos também se deve pelo fato de que quanto mais o tempo passar, mais difícil será a oportunidade de encontrar bens para saldar a dívida.

Ressalta-se que é necessária a cautela ao realizar as atividades forenses para que o direito e os deveres de todos possam ser zelados e cumpridos. Assim, ao se tratar da esfera individual do sócio-administrador, evidenciar-se-á que deve haver equilíbrio na relação de execução, uma vez que a lide deve ser célere e objetiva a fim de resguardar a dignidade humana e, por consequência, será destacada a aplicação dos princípios constitucionais como norteadores do processo.

\section{DA EXECUÇÃO FISCAL}

Neste capítulo, visa-se estudar o trâmite das ações de execução fiscal, aliada à importância da observância dos princípios norteadores do procedimento. Assim, será demonstrado que é necessário destrinchar a forma do poder de tributar por meio das limitações impostas pelos princípios atinentes à matéria para se obter um procedimento mais célere, justo e coerente.

\subsection{Do procedimento da execução fiscal}

As ações de execução fiscal visam efetuar a cobrança de créditos públicos que deixaram de ser recolhidos pelos contribuintes, tendo como titular a Fazenda Pública, compreendendo competências relativas à União, aos Estados, ao Distrito Federal, aos Municípios e às respectivas Autarquias. Salienta-se que a inadimplência desses valores prejudica toda a coletividade, que fica privada do uso desses recursos.

Os comandos legais do procedimento especial encontram-se previstos na Lei de Execução Fiscal n. 6.830/80 (LEF), no Código Tributário Nacional (CTN), Lei n. 5.172/66, em súmulas, informativos, dentre outras leis esparsas. A Lei de Execução Fiscal, Lei n. $6.830 / 80$, em seu art. $1^{\circ}$, prevê que é uma execução ju- 
dicial denominada de execução fiscal (arts. $4^{\circ}, 12,25$ e 26) e que "[...] é a execução singular por quantia certa, com base em título executivo extrajudicial, constituído pela certidão de dívida ativa regularmente inscrita, de caráter expropriatório, que se realiza no interesse da Fazenda Pública [...].” (PACHECO, 2009, p.10).

Nesse mesmo sentido é o entendimento de Humberto Theodoro Júnior (2016), o qual estabelece uma conexão entre a sistemática prevista nas ações de execução fiscal com as previstas no Código de Processo Civil. Aponta que há diferença no procedimento no que concerne às peculiaridades e aos privilégios inerentes ao crédito fiscal ante a necessidade de abreviação da satisfação do direito da Fazenda Pública. Ressalta-se que essa é a ideia original do legislador, tendo em vista a sua presença no item 24 da Exposição de Motivos (THEODORO JÚNIOR, 2016).

Desse modo, havendo lacunas para serem preenchidas no procedimento fiscal, estas poderão aplicar o previsto pelo Código de Processo Civil (CPC). Destaca-se que o conteúdo legislativo de ambos os procedimentos é harmônico, havendo um respeito pela isonomia na normatização jurídica.

Ainda, em se tratando de um processo de execução, há a necessidade de o magistrado observar a igualdade de tratamento das partes perante a lei, conforme preceitua o art. $5^{\circ}$ da Constituição da República Federativa do Brasil (CRFB). Assim, os direitos do credor devem ser atendidos por meio de um procedimento executório adequado, em que se observem as garantias individuais do executado, na medida em que haja a dilapidação de seu patrimônio para pagamento das dívidas.

Ressalta-se que, em se tratando de garantias individuais do executado, deverá haver respeito ao regular trâmite judicial, porquanto o ato de citação é preferivelmente no modo pessoal, facultado ser por edital/ficta, apenas nos casos excepcionais, 
quando tiverem sido esgotados os meios de obter a sua localização. Ainda, há de se observar a necessidade de permitir a apresentação de embargos no meio executório a fim de resguardar o direito de apresentação de defesa.

Acerca das penhoras, o procedimento judicial possibilita que o executado faça a indicação dos bens que poderão garantir a execução, tendo a sua forma prevista no art. $9^{\circ}$ da LEF, com preferência na indicação de valores monetários. Contudo, caso haja a penhora de bens indicados pelo credor, ou de maneira impositiva judicial, deverá ser viabilizada a análise para substituição da penhora, desde que observado o poder de garantia da execução e da onerosidade que pode recair sobre o executado no caso de permanência pré-existente.

Com relação ao resguardo da segurança jurídica do pleito, o levantamento da restrição ou a liberação de valores depositados em subconta vinculada ou fiança bancária deverá ocorrer apenas após o trânsito em julgado da decisão, em conformidade com o art. 32, § $2^{\circ}$, da LEF, salvo pedido expresso pelo credor.

Salienta-se que a execução fiscal não busca a satisfação apenas de créditos tributários. Existem outras dívidas ativas que não possuem esse caráter, conforme estabelece o art. 39, § $2^{\circ}$, da Lei n. 4.320/64:

Art. 39. Os créditos da Fazenda Pública, de natureza tributária ou não tributária, serão escriturados como receita do exercício em que forem arrecadados, nas respectivas rubricas orçamentárias. (Redação dada pelo Decreto Lei $\mathrm{n}^{\mathrm{o}} 1.735$, de 1979)

$\S 2^{\circ}$ - Dívida Ativa Tributária é o crédito da Fazenda Pública dessa natureza, proveniente de obrigação legal relativa a tributos e respectivos adicionais e multas, e Dívida Ativa não Tributária são os demais créditos da Fazenda Pública, tais como os prove- 
nientes de empréstimos compulsórios, contribuições estabelecidas em lei, multa de qualquer origem ou natureza, exceto as tributárias, foros, laudêmios, alugueis ou taxas de ocupação, custas processuais, preços de serviços prestados por estabelecimentos públicos, indenizações, reposições, restituições, alcances dos responsáveis definitivamente julgados, bem assim os créditos decorrentes de obrigações em moeda estrangeira, de subrogação de hipoteca, fiança, aval ou outra garantia, de contratos em geral ou de outras obrigações legais. (Incluído pelo Decreto Lei $n^{0} 1.735$, de 1979) (BRASIL, 1964).

Dito isso, verifica-se que, por ser a Fazenda Pública a titular da ação, o objeto da execução fiscal visa garantir que os anseios sociais sejam atendidos de forma justa e correta por meio de um procedimento mais célere. Assim, busca-se melhorias a favor de toda a sociedade com cobrança de tributos e coibição de atos ilícitos ante a aplicação de sanções, ao exemplo das multas, para a sua não reiteração e consequente prejuízo coletivo.

\subsection{Dos princípios norteadores e das espécies do poder de tributar}

O procedimento da execução fiscal segue os princípios basilares constituídos na Constituição da República Federativa do Brasil (CRFB), a qual estabelece as designações e as competências do poder de tributação à União, aos Estados, ao Distrito Federal e aos Municípios. Dessa forma, a fim de facilitar a tramitação judicial em processos que possuem andamentos específicos, o ordenamento jurídico brasileiro especializa a área de atuação fiscal para o direito tributário, o qual é um procedimento que visa a retomada de valores para os cofres públicos. Considerando tratar-se de execução de créditos públicos, há algumas peculiaridades que precisam ser observadas e distinguidas dos demais procedimentos. 
As peculiaridades citadas surgem com a constituição do tributo e se desenvolvem durante o procedimento de execução, tendo como premissas gerais os arts. n. 145 a 149-A da CRFB. Desse modo, verifica-se a existência de cinco espécies tributárias, conforme descreve Leandro Paulsen (2009, p. 36, grifo nosso):

a) impostos. a.1. nominados (arts. 145, I, 153, 155, 156). a.2. residuais (art.154, I). a.3. extraordinários de guerra (art. 154, II). b) taxas. b.1. de poder de polícia (art. 145, II, primeira parte). b.2. de serviços públicos específicos e divisíveis (art. 145, II, segunda parte). c) contribuição de melhoria (art. 145, III). d) contribuições especiais. d.1. gerais (art.149, primeira parte, e $\S \S$ $2^{\circ}, 3^{\circ}$ e $4^{\circ}$ ). d.1.2 de seguridade social. d.1.2.1. nominadas (art.149, primeira parte, e $\S \S 2^{\circ}, 3^{\circ}$ e $4^{\circ} \mathrm{c} / \mathrm{c}$ art.195, I, II, III). d.1.2.2. residuais (art.149, primeira parte, c/c art. 195, $\S 4^{\circ}$ ). d.1.2.3. de previdência do funcionalismo público estadual, distrital e municipal $\left(149, \S 1^{\circ} / \mathrm{EC}\right.$ 41/03). d.2. de intervenção no domínio econômico (art. 149 , segunda parte, e $\S \S 2^{\circ}, 3^{\circ}$ e $4^{\circ}$ ). d.3. do interesse das categorias profissionais ou econômicas (art. 149, terceira parte). d.4 de iluminação pública municipal e distrital (art. 149-A/EC no 39/02). e) empréstimos compulsórios. e.1. extraordinários de calamidade ou guerra (art. 148, I). e.2. de investimento (Art. 148, II).

A constituição do crédito tributário também deve observar os princípios atinentes à matéria. É o caso da anterioridade tributária, a qual é a "[...] inequívoca garantia individual do contribuinte, implicando que sua violação produzirá irremissível vício de inconstitucionalidade." (SABBAG, 2017, p.104).

Há também o princípio da isonomia tributária, que é conhecido como da proibição dos privilégios odiosos, estando previsto no art. 150, inciso II, da CRFB, o qual veda à União, aos Estados, ao Distrito Federal e aos Municípios "[...] instituir tratamento desi- 
gual entre contribuintes que se encontrem em situação equivalente, proibida qualquer distinção em razão de ocupação profissional ou função por eles exercida, independentemente da denominação jurídica dos rendimentos, títulos ou direitos". Assim, "A regra da igualdade (ou da isonomia) consiste senão em aquinhoar igualmente aos iguais e desigualmente aos desiguais, na medida em que se desigualam." (SABBAG, 2017, p.168).

Destarte, para ocorrer a garantia de preservação dos direitos atinentes ao contribuinte, como é o caso da capacidade contributiva, o caso deverá ser analisado na forma concreta, passando a existir maior razoabilidade e proporcionalidade no poder de tributar ante as particularidades sociais do local e do momento estudado. Por consequência, ocorrerá maior proteção ao indivíduo e à sociedade, evitando injustiças nas cobranças efetuadas pelas Fazendas Públicas.

Há, ainda, o princípio da irretroatividade tributária e o da vedação de confisco. Tais princípios são limitadores do direito de tributar, estando o primeiro previsto pelo art. $5^{\circ}, \mathrm{XXXVI,} \mathrm{e}$ art. 150, III, alínea "a", da CRFB, e o segundo, no art. 150, IV, do mesmo diploma legal.

O objetivo central desses dois princípios é o da proteção do cidadão para que haja uma cobrança justa e já esperada, ou seja, que o tributo não ocorra de forma espontânea, devendo ser decorrentes de previsão em lei. Desse modo, a irretroatividade, como regra, é proibida, pois, "[...] enquanto a lei deve atingir fatos a ela posteriores, a lei tributária, em idêntica trilha, deve atingir fatos geradores a ela subsecutivos." (SABBAG, 2017, p. 244).

Em relação aos princípios gerais do direito normativo brasileiro, com a promulgação da Emenda Constitucional $\mathrm{n}$. 45/04, pela reforma do judiciário, garantiu-se maior segurança tanto no âmbito administrativo quanto no judicial com 
relação à duração razoável do processo, em especial à celeridade da tramitação.

Assim, o procedimento fiscal utiliza-se da celeridade processual, que se encontra normatizado na CFRB, art. $5^{\circ}$, inciso LXXVIII, garantindo que "[...] a todos, no âmbito judicial e administrativo, são assegurados a razoável duração do processo e os meios que garantam a celeridade de sua tramitação." (BRASIL, 1988). Tal princípio é aliado ao da economia processual, o qual encontra previsão no art. 139, II, do CPC/2015, prevendo que "O juiz dirigirá o processo conforme as disposições desse Código, incumbindo-lhe:[...] II - velar pela duração razoável do processo.” (BRASIL, 2015).

Dessa forma, a atuação dos princípios em conjunto permite que o processo chegue em um resultado útil com o uso de mínimo esforço processual, gerando economicidade monetária no que tange ao andamento da lide e à diminuição do desgaste psicológico das partes ante a ansiedade gerada pelo aguardo de julgamento das ações.

Como consequência, haverá também a aplicação do princípio da efetividade, que, na execução fiscal, pela aplicação de todos os princípios anteriormente listados, promoverá o sentimento de justiça social em vista do bom andamento de seu procedimento específico, que é em pró de toda a coletividade.

Havendo tributação em excesso, caberá ao intérprete valer-se dos elementos normativos, sejam derivados diretamente da Carta Magna ou não, e, ainda, deverá fazer uso dos princípios atinentes à matéria tributária (isonomia tributária, capacidade contributiva, razoabilidade e proporcionalidade) para de fato verificar os efeitos de confisco gerados no caso concreto (SABBAG, 2017, p. 296).

Logo, não poderá o ente tributante efetuar cobranças desproporcionais, desarrazoadas e sem fundamentação legal, devendo 
ter prévia cominação legal e observância às peculiaridades da constituição de cada crédito fiscal, seja de origem tributária, seja decorrente de uma penalidade aplicada, como é o caso da multa.

Dito isso, é possível visualizar que os princípios, nessa análise, possuem como finalidade a proteção do indivíduo em face dos abusos que possam vir a existir no ato de tributar. Salienta-se que essa proteção está aliada à perspectiva de satisfação do sistema tributário brasileiro, ou seja, deve-se garantir o equilíbrio da relação jurídica tributária com resguardo dos direitos homogêneos individuais ante a cobrança e o recolhimento monetário aos cofres públicos por meio da arrecadação de impostos, taxas e aplicação de multas.

\section{DO INCIDENTE DE DESCONSIDERAÇÃO DA PERSONALIDADE JURÍDICA}

O presente capítulo visa estudar o surgimento e a normatização do incidente de desconsideração da personalidade jurídica no direito brasileiro ante a necessidade de redirecionamento do feito para promover amplitude na busca de bens para quitação dos créditos executados.

\subsection{Da necessidade de normatização do incidente}

Com a constatação de inúmeros casos de insolvência em muitas empresas no território nacional, o direito brasileiro, por meio do uso de analogias e da jurisprudência, já estava permitindo que os credores buscassem a responsabilidade dos administradores legais da pessoa jurídica no âmbito de seus patrimônios pessoais, desde que houvesse a comprovação de responsabilidade daqueles.

Dessa forma, não havendo um procedimento próprio para apurar a real necessidade de desconsideração da personalidade e auferir a responsabilidade correta aos sócios-administradores, por vezes, acabava ocorrendo atropelo no deslinde 
do feito. Essa falta de cuidado restringia o contraditório e a ampla defesa dos envolvidos, podendo resultar em ilegalidade dos atos processuais.

A possibilidade do redirecionamento surge a partir da teoria da desconsideração da personalidade jurídica (disregard doctrine), a qual aponta como sendo responsável o fato de a pessoa jurídica praticar fraudes e abusos de direito em detrimento dos credores. Essa teoria vem sendo utilizada desde o final dos anos de 1960, ante os estudos de Rubens Requião, autorizando que os magistrados estendam a responsabilidade patrimonial pelos débitos da empresa aos seus administradores (GONÇALVES, 2018, p. 253).

As primeiras aplicações dessa doutrina ocorreram em observância à legislação existente. No caso fiscal, cita-se o art. 135 do Código Tributário Nacional, que visa à proteção dos créditos públicos ante os atos de ingerência da pessoa jurídica. Sobre a legalidade da aplicação, há também o art. 28 do Código de Defesa do Consumidor, o qual reitera o fato de que a má administração e seus consectários legais autorizam o redirecionamento do feito em face dos seus sócios, além de objetivar a proteção da parte mais vulnerável em uma relação consumidíssima, ou seja, o próprio consumidor, quando “[...] houver abuso de direito, excesso de poder, infração da lei, fato ou ato ilícito ou violação dos estatutos ou contrato social." (BRASIL, 1990).

O Código Civil expõe, em seu art. 50, que "Em caso de abuso da personalidade jurídica, caracterizado pelo desvio de finalidade, ou pela confusão patrimonial", o magistrado poderá, mediante pedido do interessado, autorizar que haja a extensão da responsabilidade que, à primeira vista, era cabível à pessoa jurídica para os bens particulares dos administradores e/ou sócios da empresa (BRASIL, 2002). 
Os dispositivos anteriormente citados possibilitaram a fundamentação às decisões da jurisprudência para permissão ao redirecionamento do feito sem que houvesse a propositura de ação judicial própria. Ainda, o próprio STJ conferia validade, nesses casos, em cumprimento de sentença, uma vez que a mera intimação do sócio já bastaria para se considerar exaurida a ampla defesa e o contraditório (DONIZETTI, 2017, p. 215). Ocasionalmente, em alguns processos, o redirecionamento acontecia sem a prévia citação dos responsáveis legais das empresas, sejam elas coligadas ou do mesmo grupo econômico, provocando cerceamento de defesa da pessoa física.

Com o passar do tempo e considerando o aumento das situações em que houve a imprescindibilidade do redirecionamento do feito em face dos sócios, "[...] a jurisprudência e a doutrina passaram a sustentar que não seria possível alcançar bens do sócio sem que houvesse um contraditório no processo em que a desconsideração era decretada.” (GONÇALVES, 2018, p. 254).

Dessa forma, a necessidade de normatização do procedimento para o ato do redirecionamento do feito em face dos sócios tornou-se imprescindível para a existência de harmonia nas decisões judiciais, resultando na efetiva proteção ao contraditório e à ampla defesa.

\subsection{Do avanço normativo ante a positivação do incidente da desconsideração da personalidade jurídica}

O Código de Processo Civil de 2015 trouxe, em seu texto, a normatização do incidente de desconsideração da personalidade, o que acabou por preencher uma lacuna deixada pelo CPC de 1973. A doutrina aduz que houve uma inovação legislativa, tendo em vista a forma positivada da "disregard doctrine", a qual já era utilizada pelo meio jurídico por meio de entendimen- 
tos jurisprudenciais, havendo, agora, maior ênfase na garantia individual do sócio. Ainda, como forma de sobreposição ao incidente, aponta-se a garantia da ampla defesa e do contraditório.

Ressalta-se que também existem os casos de desconsideração inversa da personalidade jurídica, em que haverá a penhora de bens da empresa em decorrência da inadimplência dos sócios daquela. Nessa situação, será aplicada a mesma regra de necessidade de prévia citação, ocasionando a cientificação das partes acerca da lide.

Assim, a fim de que sejam resguardados os direitos individuais, o credor, ao pedir o redirecionamento da demanda, seja por meio da petição inicial ou em caráter incidental, terá o deferimento do pedido condicionado à prévia citação do sócio ou da pessoa jurídica (art. 134, § $2^{\circ}$, parte final, e art. 135 do CPC). Dessa forma, será evitada a realização de constrição judicial dos bens da pessoa jurídica em decorrência de dívidas pessoais dos sócios (desconsideração inversa) ou dos bens pertencentes aos sócios por dívida contraída pela pessoa jurídica, de maneira que tenha inviabilizado a sua defesa (DONIZETTI, 2017, p. 215).

O pedido deve observar o que preconiza o art. 134 do CPC, podendo ser requerido no processo de conhecimento, no cumprimento de sentença ou na execução fundada em título extrajudicial. Ainda, conforme prevê o art. 1.062 da Lei n. 9.099/90, poderá ser pleiteado também nos casos do Juizado Especial, sendo que, para esses casos, não é necessário aguardar a sentença para realizar o pedido. Assim, o credor poderá requerer a responsabilização por meio da petição inicial, em conformidade com $\S 2^{\circ}$ do dispositivo anteriormente citado, não havendo necessidade de instauração de incidente para tanto (DONIZETTI, 2017, p. 214).

Sobre os requisitos, além do art. 134 do CPC, deve-se levar em consideração o art. 50 do $\mathrm{CC}$, que dispõe acerca da teoria maior da desconsideração, que preconiza que também 
deverá preencher "(i) o requisito objetivo, que consiste na insuficiência patrimonial do devedor; e (ii) o requisito subjetivo, consistente no desvio de finalidade ou confusão patrimonial por fraude ou abuso de direito.” (DONIZETTI, 2017, p. 215). Ressalta-se que, para o deferimento, nesses casos, é necessário observar a aplicação do requisito objetivo em conjunto com algum de meio subjetivo. Assim, a teoria da desconsideração poderá ocorrer de forma plena.

Contudo, não se deve confundir a desconsideração inversa com a simples desconsideração da personalidade jurídica. A primeira ocorre quando o sócio possui dívidas e o credor, para vê-las saldadas, socorre-se do patrimônio da pessoa jurídica. Já a segunda se refere, conforme já explanado, aos casos em que há desconsideração da autonomia entre o patrimônio da empresa e dos seus sócios, possibilitando a penhora de bens da pessoa física, fato que objetiva evitar que a pessoa jurídica venha a ser utilizada como instrumento para fraudar a lei ou para ocorrências de abuso do direito (MARINONI; ARENHART; MITIDIERO, 2019, p. 293).

Adamais, o incidente possibilita para que "[...] sejam apuradas as razões pelas quais o direito material autoriza a responsabilização de pessoas naturais por atos praticados por pessoas jurídicas, sujeitando, assim, os bens do sócio aos atos executivos [...].” (BUENO, 2019, p. 322).

Destarte, para a preservação do contraditório e da ampla defesa, sendo instaurado o incidente, “[...] a pessoa jurídica ou o sócio - conforme o caso - será citada para apresentar defesa e, se necessário, requerer as provas cabíveis no prazo de quinze dias. A regra vale quando o requerimento se der de forma incidental." (DONIZETTI, 2017, p. 216).

Dessa forma, verifica-se que "O que o CPC de 2015 exige, destarte, é que as razões de direito material que justificam 
a responsabilização do sócio pela pessoa jurídica (e vice-versa, no caso da 'desconsideração inversa') sejam apuradas (e decididas) em amplo e prévio contraditório." (SCARPINELLA, 2019, p. 232).

Após a fase instrutória, conforme prevê o art. 1.015, inciso IV, do CPC, o incidente será resolvido por decisão interlocutória, sendo cabível agravo de instrumento. Havendo decisão proferida pelo relator, em vista do art. 1.021 do CPC, caberá agravo interno, conforme previsto no art. 136 do CPC.

Se houver a constatação de fraude à execução, preconiza o art. 137 do CPC que, "Acolhido o pedido de desconsideração, a alienação ou a oneração de bens havida em fraude de execução será ineficaz em relação ao requerente.” (BRASIL, 2015). Assim, de maneira geral, a fraude à execução será caracterizada quando o devedor alienar os bens durante o deslinde da demanda, sendo que a fraude cometida pelos sócios será apurada após a concretização da responsabilização pela dívida do devedor original, ou seja, quando do efetivo redirecionamento (MARINONI; ARENHART; MITIDIERO, 2019, p. 295).

$\mathrm{O}$ deslinde do incidente demonstra que visa promover a garantia de proteção individual das partes envolvidas na lide, tendo por ineficazes os atos praticados após a citação do responsável, seja em forma de alienação ou oneração dos bens pelo sócio/sociedade, em conformidade com os arts. 137 e 792, § 3ㅇ, do CPC (CÂMARA, 2017, p. 99).

Ante o exposto, em vista da normatização do incidente da desconsideração da personalidade jurídica pelo Código de Processo Civil de 2015, constata-se que se viabilizou a mesma unificação do procedimento em todo o território nacional. Dessa forma, há maior garantia de proteção aos credores e coibição de atos fraudulentos por parte dos sócios-administradores 
das empresas em garantia da ordem legal, além de visar ao contraditório e à ampla defesa.

\section{DA NÃO APLICAÇÃO DO INCIDENTE DE DESCONSIDERAÇÃO DA PERSONALIDADE JURÍDICA NAS AÇÕES DE EXECUÇÃO FISCAL}

Por oportuno, a fim de esclarecer e dirimir dúvidas, antes de se adentrar no mérito do título exposto, há de se distinguir o direito material ao direito de ação. Isso porque, conforme ensina Gonçalves, a jurisdição é inerte, ou seja, necessita da decisão do detentor do direito material em querer buscar uma resposta do judiciário, o qual é feito por meio de uma ação. Esse mecanismo irá provocar o Judiciário para dar uma resposta, ou seja, um provimento ou uma tutela jurisdicional. Se houver esse movimento do judiciário, terá início a formação de um processo por meio de uma relação processual entre as partes e o Estado, o qual se desenvolverá de acordo com o procedimento estabelecido em lei, por certo tempo, ocasionando na solução do conflito de interesses por meio do poder exclusivo atribuído ao Estado (GONÇALVES, 2018, p. 162).

No caso das ações fiscais, o processo observará o trâmite diferenciado encontrado no procedimento estabelecido em legislações especiais. Nesse rumo, o Código Tributário Nacional, no seu art. 121, preconiza que o sujeito passivo da obrigação tributária poderá ser o contribuinte ou o responsável, em que "A legitimação passiva para execução fiscal suscita algumas controvérsias porque, não raro, a Fazenda ajuíza execução fiscal em litisconsórcio passivo, incluindo a sociedade, o sócio-administrador e os demais sócios." (CARNEIRO, 2018, p.138).

Acerca da possibilidade de redirecionamento das execuções fiscais em face dos seus responsáveis legais, há previsão legal 
no art. 134 do CTN, o qual "Trata-se de disposição de natureza formal, instrumento que viabiliza o direito substancial, direito material este que já existe no CTN, especialmente os arts. 128, 134 e 135." (CASSONE; ROSSI; CASSONE, 2017, p. 285).

Ressalta-se que a responsabilidade tributária poderá ser reconhecida nas hipóteses de comprovação da ocorrência de prática de ato de gerência ou administração com excesso de poderes, infração à lei ou ao estatuto, e, ainda, na dissolução irregular da sociedade, sendo que, para isso, basta que não exerça mais as suas atividades no endereço cadastral, bem como que inexista bens livres e desembaraçados de sua propriedade.

Ainda, a Súmula 435 do STJ prevê que "Presume-se dissolvida irregularmente a empresa que deixar de funcionar no seu domicílio fiscal, sem comunicação aos órgãos competentes, legitimando o redirecionamento da execução fiscal para o sócio-gerente." (BRASIL, 2010).

Ademais, "Compete ao direito material estabelecer quais são as exigências para que se possa aplicar a desconsideração da personalidade jurídica.” (GONÇALVES, 2018, p. 253).

Em se tratando de incidente processual, que "[...] é uma questão controversa secundária e acessória que surge no curso de um processo e que precisa ser julgada antes da decisão do mérito da causa principal." (CONSELHO NACIONAL DE JUSTIÇA, 2020), demonstra ser dispendioso frente ao que preconiza a celeridade do trâmite fiscal.

Dito isso, considerando que a Execução Fiscal possui um procedimento com regras próprias em vista de objetividade na celeridade e economia processual, é que a abertura de um Incidente de Desconsideração da Personalidade Jurídica (art. 133 e seguintes do CPC/2015) torna-se inviável ao caso. Ademais, a demora no redirecionamento das execuções fiscais 
poderá ocasionar danos ao erário ante a possibilidade de o indivíduo se desfazer dos seus bens com intuito fraudulento.

Dessa forma, considerando que o interesse principal do trâmite fiscal é o da quitação dos créditos públicos constituídos, o decurso do tempo despendido na abertura do incidente poderá dificultar ainda mais o encontro de bens para saldar a dívida. Por vezes, algumas situações fazem com que o credor acabe por ingressar com a ação em face dos sócios das empresas em vez de realizar a desconsideração primeiramente. Por conseguinte, a fim de garantir um procedimento justo, na desconsideração da personalidade jurídica é preciso esgotar as possibilidades da empresa em quitar o seu débito para posteriormente ingressar na esfera individual dos seus responsáveis legais.

A fim de dirimir dúvidas acerca da inviabilidade de aplicação do instituto, a Escola Nacional de Formação e Aperfeiçoamento de Magistrados (ENFAM) editou o enunciado $\mathrm{n}^{\circ}$ 53, o qual prevê que "O redirecionamento da execução fiscal para o sócio-gerente prescinde do incidente de desconsideração da personalidade jurídica previsto no art. 133 do CPC/2015." (ESCOLA NACIONAL DE FORMAÇÃO E APERFEIÇOAMENTO DE MAGISTRADOS, 2015).

No mesmo sentido, o Fórum de Execuções Fiscais da Segunda Região (FOREXEC), edição 2015, publicou o enunciado $\mathrm{n}^{\circ} 6$, que estabelece que "A responsabilidade tributária regulada no artigo 135 do CTN não constitui hipótese de desconsideração da personalidade jurídica, não se submetendo ao incidente previsto no artigo 133 do CPC/2015." (ESCOLA DA MAGISTRATURA REGIONAL FEDERAL, 2015).

Dessa forma, pela preservação e respeito ao trâmite processual especial previsto na Lei de Execução Fiscal, a qual também preza pelo contraditório e pela ampla defesa do con- 
tribuinte, sob pena de cerceamento de defesa, constata-se a impossibilidade de aplicação do instituto da desconsideração da personalidade jurídica no âmbito dessas execuções.

Frisa-se que o responsável pelos tributos deixados pela pessoa jurídica será, primeiramente, o sócio-administrador, tendo em vista que cabia a ele os atos de gestão e gerência, e, em situações como de falecimento ou retirada da administração, os demais sócios também poderão ser responsabilizados pelos créditos fiscais.

Ainda, é entendimento do STJ, conforme anteriormente demonstrado pela Súmula 435, que basta uma certidão expedida pelo Oficial de Justiça, à qual é revestida de fé pública, demonstrando que a sociedade se dissolveu irregularmente, sem honrar o pagamento da dívida com o fisco, para autorizar o redirecionamento do feito para o sócio-gerente da devedora que exercia o poder de gestão, à época da constatada da infração à lei.

De fato, muitas empresas acabam fechando sem comunicação ao fisco. Desse modo, não sendo localizada no endereço indicado na inscrição Fazendária ou no seu endereço tradicional, será constatada a dissolução irregular da empresa, sendo possível a citação dos sócios na ação de execução, que são os responsáveis pela dívida social. Ressalta-se que cabe ao contribuinte manter o seu cadastro atualizado (BRASIL, 2010), devendo informar à Fazenda Pública qualquer alteração consubstancial na situação fática que a pessoa jurídica venha a sofrer.

Salienta-se que a possibilidade de inclusão dos sócios no polo passivo da demanda não se confunde com o que preconiza a Súmula 392 do STJ, a qual disciplina que "A Fazenda Pública pode substituir a certidão de dívida ativa (CDA) até a prolação da sentença de embargos, quando se tratar de correção de erro material ou formal, vedada a modificação do sujeito passivo da execução." (BRASIL, 2009). Isso porque 
não é uma simples alteração do sujeito passivo, mas sim um redirecionamento revestido de validade ante as escusas e o inadimplemento da empresa perante o fisco.

Ainda, nos casos em que a pessoa jurídica é dissolvida irregularmente, a prescrição quinquenal se inicia após a ciência do credor acerca desse fato, conforme precedentes jurisprudenciais do STJ e do Egrégio Tribunal de Justiça de Santa Catarina. Assim, não poderá haver o redirecionamento do feito em face dos sócios se já tiver passado o prazo da prescrição, devendo a Fazenda Pública estar atenta ao deslinde processual, pois o direito não socorre quem dorme.

O STJ, por meio do julgamento do REsp n. 1.520.257-SP, Informativo $\mathrm{n}^{\circ} 0564$, de 15 a 30 de junho de 2015 , decidiu que, para haver de fato o redirecionamento ao sócio, deve-se comprovar que ele exercia o posto de gerência no momento da dissolução, pois ali se dá a materialização do fato gerador e ou do vencimento do tributo (BRASIL, 2015). Ainda, fixou que o encerramento irregular da empresa permite a presunção de permanência do sócio na administração da sociedade (art. 135, caput, III, CTN c/c Súmula 435/STJ). Dessa forma, evidenciou que a infração à lei tributária é o que desencadeia a responsabilidade.

Além disso, evidencia-se que haverá maior responsabilidade sobre o magistrado que analisará o pedido de redirecionamento, tendo em vista que se dará dentro dos atos executórios fiscais. No caso do redirecionamento direto, o juiz deverá certificar-se de que a pessoa indicada pelo fisco era o sócio-administrador/representante da empresa, caso contrário, havendo o redirecionamento para outro que não detinha o poder de gestão, estar-se-á perante um ato ilegal

Tratando-se de redirecionamento do feito em face do sócioadministrador, em vista do princípio constitucional da dignidade 
humana, enquanto não houver a efetiva citação, não será possível realizar a penhora em contas de sua titularidade, pois esse sócio precisa tomar a ciência acerca dos novos rumos da execução. Caso não sejam observados os caminhos legais, a penhora será inválida diante do seu caráter irregular, pois tal ato poderá trazer consequências sérias para a pessoa que tiver seus bens constritos, uma vez que se presume o aborrecimento e o desgaste por quem carrega processos pendentes de resolução.

Verifica-se que, novamente, o sistema judiciário prima pela segurança jurídica e proteção dos créditos públicos, uma vez que são destinados ao uso comum do povo, sem deixar de lado a segurança jurídica dos atos judiciais. Ademais, frisa-se que a forma de redirecionamento para o sócio-gerente também é uma maneira de proteção dos demais envolvidos na questão jurídica, que seriam os demais sócios sem caráter de administração e decisão da sociedade, pois poderiam estar alheios às decisões tomadas pelo administrador da empresa e, assim, serem prejudicados se houvesse o redirecionamento da execução também para as suas pessoas.

Destarte, verifica-se que o redirecionamento do feito na esfera fiscal é nada mais nada menos que uma maneira de se conseguir a quitação dos créditos públicos por meio de ampliação dos meios de buscas de bens para satisfação da execução.

Ante o exposto, constata-se que, de fato, é inviável a aplicação do instituto do incidente da desconsideração da personalidade jurídica no âmbito da execução físcal, tendo em vista que esta possui rito próprio que impede a abertura de um incidente processual, pois se baseia nos princípios de duração razoável do processo, da celeridade, da economia e da segurança jurídica, devendo haver a desconsideração na própria execução com observância do contraditório e da ampla defesa. 


\section{CONCLUSÃO}

No presente trabalho, retratou-se acerca da importância trazida pelo Código de Processo Civil de 2015 em vista da normatização do incidente de desconsideração da personalidade jurídica, ante a necessidade de uniformidade e adequação dos procedimentos que se encontram codificados pelo direito. Asseverou-se que tal instituto tem como premissa promover a garantia do contraditório e da ampla defesa aos devedores incidentais.

Apontou-se que, ante os entendimentos proferidos pela ENFAM, pelo FEREXEC e pelos tribunais por meio de suas decisões, é inviável a abertura do referido incidente processual no âmbito fiscal. Demonstrou-se que isso se justifica em vista de que se trata de um procedimento que visa à celeridade jurisdicional, pois tem como objeto a cobrança de créditos públicos.

Dessa forma, considerando que a titular da ação é a Fazenda Pública, a qual atua em pró de toda a sociedade, asseverou-se que o redirecionamento do feito em face dos sócios-administradores da empresa deve ser realizado dentro da própria execução. Frisou-se que isso se justifica ante os princípios da celeridade, da eficiência, da duração razoável do processo, da economicidade e da não morosidade das ações de execução fiscal.

Ainda, demonstrou-se que o rito de redirecionamento no procedimento fiscal se dá de forma semelhante ao do incidente, uma vez que é necessário promover o contraditório e a ampla defesa da pessoa redirecionada. Desse modo, o magistrado deve atuar com maior zelo possível a fim de evitar qualquer nulidade processual e consequente irregularidade tanto nos redirecionamentos quanto nas penhoras que venham a ocorrer. Assim, foi possível constatar que, quando houver confusão patrimonial, desvio de finalidade e dissolução irregular da sociedade nas ações de execução fiscal, se poderá promover o redirecionamen- 
to em face dos seus sócios, primeiramente ao administrador, a fim de ampliar o rol de bens para satisfação da dívida.

Pelo exposto, destacou-se que o uso dos princípios constitucionais é aplicado de forma intrínseca no procedimento para garantir que o executado seja ouvido durante o processo de forma igualitária, garantindo a dignidade da pessoa humana. Por fim, é possível concluir que a não aplicação do incidente da desconsideração da personalidade jurídica no âmbito da execução fiscal garantirá a existência de uma execução que observará a celeridade para quitação dos créditos cobrados, sem deixar de lado os direitos individuais da pessoa física, a qual passou a fazer parte da lide.

\section{REFERÊNCIAS}

BRASIL. [Constituição (1988)]. Constituição da República Federativa do Brasil. Brasília, DF, Senado, 1988. Disponível em: http://www. planalto.gov.br/ccivil_03/Constituicao/Constituicao.htm. Acesso em: 5 maio 2020 .

BRASIL. Lei n 13.105, DE 16 de março de 2015. Novo Código de Processo Civil. Brasília, DF: Presidência da República, 2015. Disponível em: http://www.planalto.gov.br/ccivil_03/_Ato2015-2018/2015/ Lei/L13105.htm. Acesso em: 5 maio 2020.

BRASIL. Lei n 5.172, de 25 de outubro de 1966. Dispõe sobre a cobrança judicial da Dívida Ativa da Fazenda Pública, e dá outras providências. Brasília, DF: Presidência da República, 1966. Disponível em: http://www.planalto.gov.br/ccivil_03/leis/16830.htm. Acesso em: 5 maio 2020

BRASIL. Lei n 6.830, de 22 de setembro de 1980. Dispõe sobre o Sistema Tributário Nacional e institui normas gerais de direito tributário aplicáveis à União, Estados e Municípios. Denominado Código Tributário Nacional pelo art. 7 do Ato Complementar n 36, de 13.3.1967. Brasília, DF: Presidência da República, 1980. Disponível em: http://www. planalto.gov.br/ccivil_03/LEIS/L5172.htm. Acesso em: 05.05.2020

BRASIL. Superior Tribunal de Justiça. REsp n. 1.520.257-SP. Recorrente Fazenda Nacional. Recorrido INFO- ON LINE Informática 
Ltda Microempresa. Relator: Ministro OG Fernandes. Órgão Julgador: $2^{\circ}$ Turma. Brasília, DF, 16 de junho de 2015. Informativo jurisprudencial, Brasília, DF, n. 0564, 15 a 30 jun. 2015. Disponível em: https://ww2.stj.jus.br/jurisprudencia/externo/informativo/?acao=pesquisar\&livre $=\mathrm{S} \% \mathrm{D} 3 \mathrm{CIO}+$ GERENTE + GER $\%$ CANCIA\&operador $=-$ mesmo\&b=INFJ\&thesaurus=JURIDICO\&p=true. Acesso em: 17 mar. 2020.

BRASIL. Superior Tribunal de Justiça. Súmula No 392. Direito Processual Civil. Execução Fiscal. Brasília, DF: Superior Tribunal de Justiça, 2009. Disponível em: https://ww2.stj.jus.br/docs_internet/revista/ eletronica/stj-revista-sumulas-2013_36_capSumula392.pdf. Acesso em: 05 maio 2020.

BRASIL. Superior Tribunal de Justiça. Súmula $\mathbf{n}^{\circ}$ 435. Direito Processual Civil. Execução Fiscal. Brasília, DF: Superior Tribunal de Justiça, 2010. Disponível em: https://scon.stj.jus.br/SCON/sumanot/toc. jsp?livre $=\% 28$ sumula $\% 20$ adj $1 \% 20 \% 27435 \% 27 \% 29$.sub. Acesso em: 5 maio 2020.

CÂMARA, Alexandre Freitas. O novo processo civil brasileiro. 3. ed. São Paulo: Atlas. 2017.

CARNEIRO, Claudio. Processo tributário administrativo e judicial. 5. ed. São Paulo: Saraiva. 2018.

CASSONE, Vittorio; ROSSI, Júlio Cesar; CASSONE, Maria Eugenia Teixeira. Processo tributário: teoria e prática. 15. ed. São Paulo: Atlas. 2018

CONSELHO NACIONAL DE JUSTIÇA. O que são incidentes. Brasília, DF: CNJ, 2020. Disponível em: https://www.cnj.jus.br/pesquisas-judiciarias/demandas-repetitivas/o-que-sao-incidentes/\#: : :text=Incidente $\% 20$ processual $\% 20 \% \mathrm{C} 3 \% \mathrm{~A} 9 \% 20$ uma $\% 20$ quest $\% \mathrm{C} 3 \% \mathrm{~A} 30$,do $\% 20 \mathrm{~m} \% \mathrm{C} 3 \%$ A 9 rito\%20da\%20causa\%20principal. Acesso em: 23 jun. 2020

DONIZETTI, Elpídio. Novo Código de Processo Civil comentado. 2. ed. Atlas: São Paulo, 2017

ESCOLADA MAGISTRATURA REGIONALFEDERAL (2. Região). Fórum de execuções fiscais: o impacto do novo Código de Processo Civil na Execução Fiscal. Rio de Janeiro: EMARF, 2015. Disponível 
em: http://www.enfam.jus.br/wpcontent/uploads/2015/10/enunciadosforexec2015.pdf. Acesso em: 9 jan. 2020.

ESCOLA NACIONAL DE FORMAÇÃO E APERFEIÇOAMENTO DE MAGISTRADOS. Enunciado 53. In: SEMINÁRIO O PODER JUDICIÁRIO E O NOVO CÓDIGO DE PROCESSO CIVIL. Enunciados aprovados. Brasília, DF: ENFAM, 2015. Disponível em: https://www.enfam.jus.br/wpcontent/uploads/2015/09/ENUNCIADOS-VERS\%C3\%83O-DEFINITIVA-.pdf. Acesso em: 9 jan. 2020

GONÇALVES, Marcus Vinicius Rios. LENZA, Pedro. Direito processual civil esquematizado. 9. ed. São Paulo: Saraiva, 2018.

MARINONI, Luiz Guilherme; ARENHART, Sérgio Cruz; MITIDIERO, Daniel. Código de Processo Civil comentado. 5. ed. São Paulo: Revista dos Tribunais, 2019

PACHECO, José da Silva. Comentários à Lei de execução fiscal. 12. ed. São Paulo: Saraiva, 2009.

PAULSEN, Leandro. Direito tributário: Constituição e Código Tributário à luz da Doutrina e da Jurisprudência. 11. ed. Porto Alegre: Livraria do Advogado; Esmafe, 2009.

SABBAG, Eduardo. Manual de direito tributário. 9. ed. São Paulo: Saraiva, 2017.

THEODORO JÚNIOR, Humberto. Lei de execução fiscal. 13. ed. São Paulo: Saraiva, 2016

Recebido em: 20/05/2020

Aprovado em: 21/07/2020 